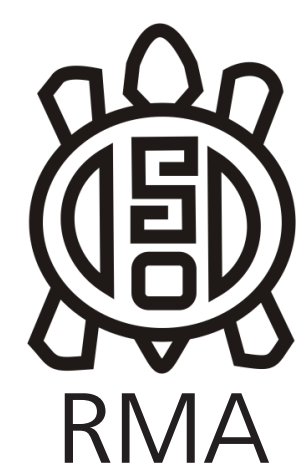

Arqueología

\title{
La vida de los objetos arqueológicos en museos históricos regionales del interior de la provincia de Buenos Aires
}

\author{
Archaeological objects in regional historical museums from Buenos \\ Aires province
}

\author{
Olivia L. Sokol*, Micaela Grzegorczyk**, Paula D. Funes**, \\ Maximiliano Tello**, Virginia M. Salerno*
}

*CONICET-Instituto de Arqueología, Facultad de Filosofía y Letras, Universidad de Buenos Aires. E-mail: olivia.I.sokol@gmail.com; vmasalerno@gmail.com

\begin{abstract}
**Instituto de Arqueología, Facultad de Filosofía y Letras, Universidad de Buenos Aires. E-mail: grzmicaela@gmail.com; funes.pauladaniela@gmail.com; maxitel82@hotmail.com
\end{abstract}

\begin{abstract}
Resumen
En la microrregión del río Salado (Buenos Aires) se han identificado múltiples prácticas en las que confluyen diferentes actores poniendo en juego dispositivos y recursos de administración -gestión y comunicación- del pasado prehispánico. En estas prácticas tienen centralidad los objetos que documentan la historia indígena como elementos que posibilitan la elaboración de diferentes narrativas. La escasa visibilidad de estos materiales en el paisaje posiciona a las instituciones museísticas como un ámbito clave. En ellas, se configuran formas públicas de representación del pasado que en ocasiones reproducen los estereotipos hegemónicos y en otras los debaten. Desde un enfoque centrado en la materialidad nos proponemos abordar las trayectorias de los conjuntos de materiales arqueológicos de cinco museos locales. Argumentamos que en estas instituciones, dichos objetos tienen un rol activo en la construcción de narrativas sobre el pasado que no se limita a su participación en exhibiciones.
\end{abstract}

Palabras clave: Enfoque Biográfico; Representaciones del Pasado; Historia Indígena; Materialidad; Microrregión del río Salado.

\begin{abstract}
Multiple practices related to administration resources of pre-Hispanic times (management and communication) have been identified in the Salado River microregion (Buenos Aires province). Different actors come together in those practices. The materials that document indigenous history are key elements in such practices since they enable the creation of different narratives about the past. Museum institutions play an important role because archaeological materials have poor visibility in the landscape. Museum's public representations of the past sometimes reproduce hegemonic stereotypes, but some other times debate those stereotypes.

We aim to study the trajectories of the archaeological material collections preserved in five local museums. We develop this research centered on a materiality perspective. Our main argument is that pre-Hispanic objects have an active role in constructing narratives about the past, and this active role goes beyond their place in the exhibitions in museums.
\end{abstract}

Keywords: Biographical Approach; Representations of the Past; Indigenous history; Materiality; Salado River Microregion.

\section{Introducción}

En la provincia de Buenos Aires, la mirada simplificadora respecto de las relaciones entre el pasado colonial y el prehispánico constituye el punto de partida de las narrativas históricas hegemónicas: lo indígena es reducido a las historias de frontera (Mandrini, 2007). A pesar de ello, en esta provincia se reconocen procesos poblacionales desde hace 12.000 años antes del presente (Flegenheimer, 2001; Politis \& Madrid, 2001;
Salerno, 2018). Esa historia se encuentra documentada por materiales arqueológicos que circulan en museos locales -públicos y privados-, y en contextos rurales integrando la cotidianeidad de los pobladores actuales. La invisibilización de los procesos poblacionales indígenas formó parte de las políticas implementadas desde fines del siglo XIX que confluyeron en la construcción de subjetividades y alteridades de la nación argentina (Briones, 2005). Al punto que en la actualidad, Buenos Aires es una provincia visibilizada como un territorio "sin 
indios" (Nagy, 2017). Estas representaciones constituyen relatos complejos cristalizados a partir de procesos conflictivos de negociación que tuvieron lugar en el marco de relaciones desiguales (Rufer, 2009). Desde un punto de vista histórico se ha planteado que tanto los museos como la arqueología contribuyeron a la elaboración y reproducción de estas narrativas mediante la gestión de objetos culturales indígenas en términos patrimoniales (Blasco, 2011; Dujovne, 1995; Podgorny, 1999; entre otros)

En la actualidad, la reducida visibilidad de la materialidad arqueológica que documenta el poblamiento prehispánico en el territorio bonaerense posiciona a las instituciones museísticas como un ámbito clave. En ellas, se configuran formas públicas de representación del pasado que en ocasiones reproducen los estereotipos hegemónicos y en otras los debaten (Ruffer, 2009). Desde la segunda mitad del siglo $X X$, algunos museos fueron repensados y revalorizados en tanto puntos de referencia en la vida urbana como ámbitos de interacción, exploración y reflexión de la cultura (Huyssen, 2002). La reorganización de estos espacios incluyó, entre otras cosas, planteos críticos en relación con los modos de representar el pasado y el presente indígena en nuestra sociedad. Como resultado, en algunas instituciones modificaron sus propuestas expositivas y/o generaron nuevas muestras (Baganoli, 2019; Balbé, 2019; Conforti \& Endere, 2012; Menares, Mora, \& Stüdemann, 2007). En estas experiencias, las vinculaciones con múltiples actores -grupos locales, especialistas, comunidades indígenas- y otras instituciones -museos, universidades, escuelas- contribuyó a diversificar los discursos elaborados (Baganoli, 2019; Conforti \& Endere, 2012; Sánchez Azcárate, 2016; entre otros).

A pesar de las renovaciones se ha observado que en muchos museos bonaerenses, al igual que sucede en otros lugares de la región pampeana y patagónica, las exposiciones con objetos culturales indígenas continúan sosteniendo representaciones estereotipadas (Rodríguez, 2013). Estas se sustentan mediante estrategias expositivas que omiten y reducen eventos específicos de la historia indígena (Crespo \& Tozzini, 2014; Nagy, 2013; entre otros) y/o sitúan dicha historia en un pasado distante y desvinculado de las historias locales (Quesada, Moreno, \& Gastaldi, 2007; Salerno \& Vigna, 2011; Sterling, 2009; entre otros). Los motivos de dichas persistencias pueden comprenderse mejor, teniendo en cuenta que las narrativas propuestas por los museos son el resultado de un inter-juego dinámico mediado por las trayectorias institucionales, la disponibilidad de recursos, la implementación de políticas culturales en tensión, y la negociación entre diferentes actores involucrados. Sin perder de vista la complejidad de estas dinámicas institucionales, buscamos profundizar las discusiones sobre las prácticas, usos y sentidos en torno a los objetos arqueológicos que integran las colecciones de museos históricos locales.

Con este fin, presentamos el caso de cinco museos del interior de la provincia de Buenos Aires ubicados en la microrregión del río Salado (Chascomús, General Belgrano, General Paz, Lezama y San Miguel de Monte). Estas instituciones incluyen en sus acervos materiales relacionados con el poblamiento indígena prehispánico de la zona, de variado tamaño y características, proveniente de colecciones privadas y excavaciones arqueológicas sistemáticas. Se trata de museos que, en términos generales, organizan representaciones de la identidad local asociada con la vida rural y diferentes acontecimientos del siglo XIX relativos al poblamiento del campo bonaerense. En estas imágenes, el pasado indígena suele ser invisibilizado. Con una mirada atenta a las trayectorias institucionales y las prácticas movilizadas en torno a los materiales prehispánicos, buscamos reconocer diferentes procesos que contribuyen a organizar las representaciones del pasado indígena local. Desde un enfoque centrado en la materialidad, discutimos en qué medida los objetos conservados $y$, en algunos casos expuestos, tienen un rol activo en la elaboración de sentidos sobre el pasado que evocan. De esta manera, nos proponemos situar en el eje del análisis el papel que cumplen los objetos en la reproducción, negociación y construcción de las narrativas sobre el pasado (Gosden, 2005; Hutson, 2002; Thomas, 1991).

\section{Objetos arqueológicos y materialidad: puntos de partida}

Este trabajo se enmarca en una investigación más amplia sobre los usos, prácticas y sentidos de la materialidad prehispánica en la microrregión que se viene desarrollando desde el año 2014 (Salerno, 2016). La misma se organiza con una estrategia mixta, antropológica y arqueológica, para abordar el carácter relacional e histórico de los materiales. Desde este enfoque se articula el análisis de registros de observaciones y entrevistas en distintos contextos, y con múltiples actores de la microrregión; junto con la revisión de material documental y relevamiento fotográfico de objetos. Los diversos registros generados se analizaron desde un enfoque que recupera una mirada dialéctica de los objetos. Entendemos que, como seres humanos, vivimos insertos en un mundo material; tanto corporal como sensorialmente estamos en contacto e interactuamos con elementos materiales y estos a su vez nos definen y moldean (Hamilakis, 2015). Los materiales son creados por las personas, pero la importancia y el poder que estos adquieren terminan trascendiendo su funcionalidad principal y permite que puedan ser redefinidos de forma dinámica.

Una característica de los objetos es que estos se encuentran atravesados por múltiples temporalidades a lo largo de su historia (Olsen, 2003). Pueden evocar el recuerdo de un pasado lejano, remitir a personas que ya 
no están, acciones que dejamos de realizar o cosas que no podemos volver a utilizar. Por estos motivos tienen el potencial de producir sensaciones y con el paso del tiempo también les asignamos historias, sentidos y agencias (Miller, 2005; Tilley, 1994). A su vez, estas historias se entrelazan con más objetos y personas (Ingold, 2007; Lucas, 2012). De este modo, los materiales se constituyen en agentes movilizadores, capaces de incidir en la realidad individual y social. En este sentido, puede decirse que el valor de los objetos conservados en los museos remite al entramado de relaciones sociales e históricas que estos acumulan (Clifford, 1995). El estudio de dicho entramado se ha sistematizado a través de un enfoque biográfico que resulta efectivo para reconocer los cambios que inciden en la relación dialéctica entre las personas y las cosas (Gosden \& Marshall, 1999), y en cómo el significado de los objetos cambia a lo largo del tiempo.

Recuperamos este abordaje en pos de analizar el lugar de los objetos arqueológicos en los museos municipales de la microrregión: Museo Pampeano de Chascomús, Museo Histórico "Marta Inés Martínez" de Ranchos (General Paz), Museo Municipal "Guardia del Monte" (San Miguel del Monte), Museo Histórico Municipal 'Alfredo Enrique Múlgura' (General Belgrano), y Museo Histórico de Lezama. Como integrantes del equipo de arqueología de la Facultad de Filosofía y Letras de la Universidad de Buenos Aires que investiga en el área desde la década de 1980, dirigido por las Dras. González y Frère, venimos trabajando en colaboración con estas instituciones realizando múltiples actividades de investigación, extensión y gestión de las colecciones arqueológicas.

Para este trabajo utilizamos registros de observaciones y entrevistas realizados en los museos entre los años 2015 y 2020. Las observaciones estuvieron dirigidas a relevar las características generales de las instituciones analizadas, las actividades que se realizan y los modos en que se gestionan las colecciones arqueológicas (tanto las exhibidas como las que no lo están). En las entrevistas indagamos la perspectiva de los trabajadores de los museos respecto de sus experiencias con los objetos arqueológicos en las instituciones. En ellas abordamos los siguientes ejes temáticos: historia del museo, diseño museográfico, el museo y la comunidad, sala de arqueología/objetos arqueológicos y visitas guiadas. A partir del relevamiento realizamos un perfil general de cada museo que nos permitió observar en las trayectorias institucionales ciertas diferencias, y similitudes en los modos de abordar las colecciones arqueológicas.

El trabajo de campo tuvo lugar en el marco de diferentes situaciones. Por un lado, se planificaron instancias de visita a los museos para realizar un relevamiento de sus exposiciones y colecciones. Además, desde el año 2018 se sostiene el seguimiento de múltiples reuniones entre los museos de la microrregión virtuales -grupo de Facebook Museos de la Cuenca del Salado- y presenciales -encuentros y jornadas de discusión-. Estos espacios, promovidos por los trabajadores de los museos, buscan generar redes de intercambio y establecer una agenda de actividades compartidas en torno a la gestión patrimonial. Su seguimiento nos permitió reconocer las estrategias que estas instituciones despliegan para desempeñarse exitosamente con escasos y/o nulos recursos. Finalmente, otra instancia de trabajo de campo se desarrolló en el marco de nuestra participación en reuniones y actividades del equipo de arqueología local que tuvieron lugar en los museos: actividades de extensión, revisión de colecciones, asesoramiento en el armado de guiones, reuniones para articular distintas formas de colaboración, entre otras. En el transcurso de los últimos seis años, estos diferentes espacios de encuentro nos permitieron reconstruir aspectos centrales de las trayectorias institucionales, así como también de las dificultades que se afrontan en su gestión municipal, y el rol de los distintos actores que se encuentran involucrados (ya sea especialistas, grupos de sociedades amigas, aficionados u otros).

En la contextualización social e histórica de los registros y entrevistas, se utilizaron diversas fuentes éditas e inéditas (escritas, fotográficas y audiovisuales). En la Tabla 1 sintetizamos la información consultada en cada institución cuyas diferencias responden a la disponibilidad de cada caso. En los archivos administrativos de los museos se relevaron memorias institucionales y cartas de donaciones -Chascomús, Gral. Belgrano y Gral. Paz- que nos permitieron reconstruir una parte de la biografía de los materiales arqueológicos, como la formación de colecciones, actividades realizadas con ellos, exposiciones y/o diseños de las mismas. Esa información se amplió en los casos en que estuvo disponible, con noticias de medios masivos locales. Además, a partir de la documentación de los archivos de los museos contextualizamos su caracterización considerando las historias institucionales. Esta tarea también se nutrió de información disponible online en sitios web de los propios museos, de los municipios y/o en blogs de turismo. Se utilizaron materiales audiovisuales donde se presentan a las instituciones. Estos fueron útiles para relevar otra manera de contar la historia institucional donde las imágenes adquieren un lugar protagónico. Asimismo, se ha considerado junto con las narrativas presentadas, la selección de imágenes y las relaciones propuestas entre ellas. Finalmente, otro tipo de material relevado fueron las publicaciones en redes virtuales (Facebook e Instagram), que en ocasiones constituyen una fuente de comunicación institucional muy activa con publicaciones diarias. En estos documentos virtuales se puede encontrar información sobre horarios de las instituciones, publicaciones de visitantes del museo, eventos -charlas o encuentros-, información sobre la localidad, reuniones con profesionales, inauguraciones, entre otras.

En conjunto estos diferentes registros nos permitieron profundizar el análisis de las múltiples temporalidades 
que portan los materiales prehispánicos y el modo en que estas se resignifican dentro de los museos. En primer lugar, abordamos las historias institucionales, los modos en que se formaron las colecciones de estos objetos en cada institución y su uso en diferentes espacios expositivos. En segundo lugar, discutimos el modo en que estos materiales impactan en las dinámicas institucionales, inclusive cuando no forman parte de exhibiciones. A partir de ello discutimos de qué manera los materiales arqueológicos en los museos de la microrregión tienen un rol activo en la elaboración de narrativas históricas.

\section{El origen de las colecciones arqueológicas de los museos de la microrregión}

Los cinco museos analizados se gestaron con el empuje de personajes referentes que pugnaron por la creación de instituciones que representaran la historia local. A partir de establecer una serie de continuidades y rupturas entre pasado y presente, los objetos albergados en estas instituciones movilizaron un proceso patrimonial (sensu Smith, 2011) dirigido a crear, recrear, y poner en tensión recuerdos, valores y significados en torno a las identidades locales. En las mismas, aquellos elementos asociados con la presencia indígena en la zona fueron categorizados como objetos arqueológicos y utilizados para señalar un momento de ruptura que da inicio a la historia local. Una parte de estos materiales tiene su origen en colecciones de particulares, mientras que otra parte ingresó a las instituciones como donaciones de hallazgos aislados realizados por vecinos. En las últimas tres décadas, dichas colecciones se acrecentaron a partir de materiales recuperados en las excavaciones arqueológicas de la zona. De diferente manera, pero en todos los casos, la construcción como objeto museístico de estas colecciones se vincula con la historia de la arqueología en la región cuyos orígenes se remontan a fines del siglo XIX.

Estas instituciones son espacios diversos y complejos no sólo en términos de infraestructura edilicia y colecciones, sino que también están atravesados por tensiones derivadas de una recurrente falta de medios económicos y de personal, así como por su articulación rotativa con las políticas públicas municipales dirigidas a la gestión cultural y/o turística. En ninguno de estos museos el personal permanente supera las cuatro personas, éstas llevan adelante las diferentes tareas junto con el trabajo intermitente de personal rotativo municipal. Esta situación implica una sobrecarga para los pocos actores que llevan adelante la gestión institucional. La misma se resuelve de forma diferente en cada institución, pero siempre con la colaboración de actores claves que participan regularmente. En algunos casos es importante la gestión de asociaciones amigas del museo conformadas por vecinos de las localidades, así como el aporte de personas que tienen vínculos personales con los trabajadores del museo. Además, en otros es importante la participación de vecinos a partir de su involucramiento en grupos de estudio que utilizan la institución como sede y/o para consultar parte de sus acervos. El conjunto de estas características incide diferencialmente en el modo en que se gestionan las colecciones, los espacios expositivos y las actividades que impulsan. Respecto a su inserción social, entre las actividades que se realizan pueden mencionarse las visitas guiadas, talleres y cursos con participación de especialistas y aficionados (locales y no locales), encuentros temáticos, dramatizaciones, entre otras. Además, en algunos casos se impulsan dispositivos -cajas didácticas, videos institucionales- mediante los cuales el museo amplía su impacto territorial "visitando" escuelas y/o parajes rurales de las localidades (Poggi \& de Arce, 2018). Los principales visitantes pueden describirse como público escolar, familias, grupos de jubilados y turistas.

Los museos de Chascomús, General Paz y General Belgrano se distinguen por su amplia disponibilidad espacial y el acervo diverso de sus colecciones. Esto se manifiesta en la cantidad de salas destinadas a exposiciones -permanentes y temporales-, y los espacios para el depósito, eventos y biblioteca. Así por ejemplo, desde el año 1972, el museo de Ranchos, también cuenta con una sala de medios audiovisuales y un laboratorio fotográfico. Este museo y el de General Belgrano, también poseen archivos que conservan documentos de los siglos XVIII, XIX y XX. En contraste, los museos de Lezama y San Miguel de Monte, aunque emplazados en edificios de reconocida trayectoria histórica local, cuentan con menor espacio para gestionar las colecciones y sus muestras. La situación del museo de Lezama es especialmente crítica, ya que funciona en un edificio con una sola habitación. En la Tabla 2 sintetizamos la información relativa a cada uno de estas instituciones.

El origen del Museo Municipal Pampeano (Chascomús) y del Museo Histórico Regional "Marta Inés Martínez" (Ranchos, partido de General Paz) debe contextualizarse a mediados del siglo XX, cuando las elites gobernantes promovieron iniciativas museográficas que conjugaron funciones recreativas y educativas dirigidas a homogeneizar

\begin{tabular}{|c|c|c|c|c|c|}
\hline & $\begin{array}{c}\text { Museo Pampeano } \\
\text { de Chascomús }\end{array}$ & $\begin{array}{c}\text { Museo Histórico } \\
\text { de Ranchos }\end{array}$ & $\begin{array}{c}\text { Museo Histórico } \\
\text { de Gral. Belgrano }\end{array}$ & $\begin{array}{c}\text { Museo Histórico } \\
\text { de Monte }\end{array}$ & $\begin{array}{c}\text { Museo Histórico } \\
\text { de Lezama }\end{array}$ \\
\hline $\begin{array}{c}\text { Memorias } \\
\text { institucionales/ } \\
\text { cartas de donaciones }\end{array}$ & $\mathrm{X}$ & $\mathrm{X}$ & $\mathrm{X}$ & $\mathrm{X}$ & $\mathrm{X}$ \\
\hline $\begin{array}{c}\text { Medios de } \\
\text { comunicación }\end{array}$ & $\mathrm{X}$ & $\mathrm{X}$ & $\mathrm{X}$ & $\mathrm{X}$ & $\mathrm{X}$ \\
\hline Páginas web & $\mathrm{X}$ & $\mathrm{X}$ & $\mathrm{X}$ & $\mathrm{X}$ & $\mathrm{X}$ \\
\hline Material audiovisual & $\mathrm{X}$ & $\mathrm{X}$ & $\mathrm{X}$ & & $\mathrm{X}$ \\
\hline Redes sociales & & & & & \\
\hline
\end{tabular}

Tabla 1. Tipo de fuentes disponibles y consultadas relacionadas con los museos analizados.

Table 1. Type of available sources and queries related to the analyzed museums. 


\begin{tabular}{|c|c|c|c|c|c|}
\hline & $\begin{array}{l}\text { MUSEO PAMPEANO DE } \\
\text { CHASCOMÚS }\end{array}$ & $\begin{array}{l}\text { MUSEO HISTÓRICO } \\
\text { DE RANCHOS }\end{array}$ & $\begin{array}{l}\text { MUSEO HISTÓRICO DE } \\
\text { GENERAL BELGRANO }\end{array}$ & $\begin{array}{c}\text { MUSEO HISTÓRICO DE } \\
\text { MONTE }\end{array}$ & $\begin{array}{c}\text { MUSEO HISTÓRICO } \\
\text { DE LEZAMA }\end{array}$ \\
\hline Ubicación & Chascomús & $\begin{array}{l}\text { Ranchos (Partido de } \\
\text { General Paz) }\end{array}$ & General Belgrano & San Miguel del Monte & Lezama \\
\hline Fecha de fundación & 1939 & 1964 & 1997 & 2001 & 1992 \\
\hline Cantidad de salas & 7 & 7 & 6 & 4 & 1 \\
\hline $\begin{array}{l}\text { Origen de materiales } \\
\text { prehispánicos }\end{array}$ & $\begin{array}{l}\text { Donaciones de hallazgos } \\
\text { aislados; colecciones } \\
\text { privadas; Grupo de } \\
\text { arqueología. }\end{array}$ & $\begin{array}{l}\text { Donaciones de } \\
\text { hallazgos aislados; } \\
\text { Grupo de } \\
\text { arqueología. }\end{array}$ & $\begin{array}{c}\text { Donaciones de } \\
\text { hallazgos aislados; } \\
\text { Colección privada; } \\
\text { Grupo de arqueología. }\end{array}$ & $\begin{array}{c}\text { Préstamo de otras } \\
\text { instituciones; } \\
\text { Donaciones de hallazgos } \\
\text { aislados; } \\
\text { Grupo de arqueología. }\end{array}$ & $\begin{array}{l}\text { Donaciones de } \\
\text { hallazgos aislados; } \\
\text { Grupo de } \\
\text { arqueología. }\end{array}$ \\
\hline $\begin{array}{l}\text { Exhibición de materiales } \\
\text { prehispánicos }\end{array}$ & $\begin{array}{c}\text { - Sala arqueológica y } \\
\text { paleontológica } \\
\text { - Sala pampeana }\end{array}$ & $\begin{array}{l}\text { Los origenes de } \\
\text { Ranchos }\end{array}$ & $\begin{array}{c}\text { - Los primeros } \\
\text { pobladores } \\
\text { - Evolución del campo }\end{array}$ & $\begin{array}{l}\text { - Guardia de Monte } \\
\text { - Periodo Federal }\end{array}$ & $\begin{array}{c}\text { Estación Patrimonio } \\
\text { Arqueológico }\end{array}$ \\
\hline
\end{tabular}

Tabla 2. Caracterización general de los museos de la microrregión analizados.

Table 2. General characterization of the microregion museums under analysis.

el relato histórico de la nación argentina (Blasco, 2007). En los pueblos de la provincia de Buenos Aires, se crearon museos con colecciones históricas, naturales, paleontológicas y/o arqueológicas (Pupio, 2005). En sus narrativas adquirió centralidad la figura del gaucho como ícono de la argentinidad estableciendo de esa manera la distinción con otros grupos sociales -especialmente indígenas e inmigrantes- (Blache, 1991-1992; Prieto, 1988). En este tipo de proyectos participaron diferentes actores entre los que se destacaron los vecinos con alto estatus social que pujaron por ampliar y multiplicar los sentidos en torno a las propuestas provinciales (García, 2011; Pupio, 2005). A pesar de los matices introducidos por los actores locales, los relatos construidos proponen un recorrido cronológico en el que la historia indígena forma parte de un pasado inicial cuya superación posibilitó el crecimiento del país.

En cuanto a la formación de colecciones de materiales prehispánicos, el Museo Pampeano de Chascomús es un caso diferente al resto de los museos analizados, ya que los primeros acervos fueron cedidos por coleccionistas y aficionados. Estas colecciones incluyen objetos cerámicos y líticos (materiales formatizados y piedra pulida) y se identifican dentro de la institución con el nombre de sus creadores: Girado-Greslebin y López Osornio. Las mismas fueron estudiadas a lo largo de todo el siglo XX, constituyéndose en una referencia de la arqueología local (Vigna \& Salerno, 2013). A pesar de que estos objetos fueron parte de los diseños iniciales del museo de 1939, no fue hasta el año 1952 cuando se expusieron en una muestra referida a "los inicios de la evolución cultural". Su sistematización fue el punto de partida de los primeros estudios arqueológicos sistemáticos llevados a cabo en la década de 1980 y centrados en lo que antaño pertenecía al territorio de Chascomús (y desde 2009, al Partido de Lezama). El vínculo sostenido con el equipo de arqueología contribuyó a incrementar las colecciones del museo.

Los materiales arqueológicos se exhiben junto con objetos paleontológicos en un espacio que fue remodelado en diferentes ocasiones en articulación con las arqueólogas ${ }^{1}$.

\footnotetext{
1 Las múltiples remodelaciones de esta sala incluyeron cambios de nombre, narrativas y selección de objetos expuestos. Entre ellas se destacan por las transformaciones implicadas la reorganización de los años 1992 y 2011 (Salerno, 2014).
}

Actualmente la sala se organiza con un criterio cronológico que ubica a los objetos paleontológicos en una temporalidad previa y distante a la arqueológica. En esta sala se muestran materiales recuperados en las excavaciones (fragmentos de alfarería, puntas de flecha, lascas, bolas de boleadora) junto con réplicas de vasijas elaboradas por ceramistas locales. En este museo también se exhiben bolas de boleadora en las salas referidas a la vida en el campo ${ }^{2}$.

En contraste con esta situación, la colección de materiales prehispánicos del museo de Ranchos no fue parte de los primeros acervos. A partir de las cartas de donaciones puede identificarse el origen de estos objetos, que mayormente se trata de elementos aislados hallados de forma fortuita en zonas rurales. Por otra parte, en las memorias institucionales se describen las primeras exposiciones de este museo, conformadas por objetos personales y armas antiguas cedidas por familias y personajes de reconocida trayectoria en la localidad. De acuerdo con las memorias institucionales, fue recién con la reorganización de las exhibiciones en el año 1978, cuando se comenzó a exponer los materiales prehispánicos en una sala dedicada a los Orígenes de Ranchos. Allí, se muestran objetos de piedra pulida: hachas y bolas de boleadora junto con la imagen de un indígena en posición dinámica, manipulando estas últimas. En dicha sala también se incluye una representación del cacique Linco Pagny acompañado de cartelería que lo describe "invadiendo las fronteras por la laguna de Ranchos", y dos mapas del actual territorio de la provincia de Buenos Aires en los que se describe en un caso "la frontera con los indios" y en el otro, la ubicación de "fuertes, fortines y reducciones". Una maqueta del fortín reconstruido en la misma localidad completa la propuesta expositiva ubicando la temporalidad de los elementos presentados en esta sala a fines del siglo XVIII. En este museo también se exhiben bolas de boleadora en un Cuarto de Sogas dedicado a conmemorar la destreza de Martín Gómez, considerado en 1989 como el "mejor soguero vivo del país" (Bona, 1989).

Diferente es la situación del Museo Histórico Municipal "Alfredo Enrique Múlgura" de General Belgrano cuyo origen se vincula a la historia de Alfredo Múlgura, un

\footnotetext{
${ }^{2}$ Relevamiento realizado el 8 de septiembre 2019.
} 
coleccionista local que en el año 1939 creó un museo privado con diversos objetos históricos, arqueológicos y paleontológicos. En las memorias se señala la donación de estos conjuntos al municipio en el año 1997 como hito fundacional del museo. Estos incluían materiales líticos provenientes de la Patagonia que habían sido obtenidos por Múlgura mediante intercambio. De acuerdo con los registros institucionales, otros materiales prehispánicos de origen local se sumaron a partir de donaciones de vecinos de la localidad que, recorriendo las orillas del río o alrededores, hallaban objetos de piedra pulida (bolas de boleadoras y morteros) y fragmentos de cerámica. Los temas de las primeras exposiciones de este museo abordaron el funcionamiento de la antigua panadería que funcionaba en el edificio donde se emplaza la institución -con muebles originales-, el Rincón Belgraneano dedicado a recordar al prócer Manuel Belgrano, la evolución del campo, la llegada del ferrocarril del sud en 1871, la presencia de inmigrantes y una sala sobre información paleontológica. En la exposición sobre la Evolución del campo se exponen bolas de boleadora junto con herramientas de tecnología agraria ${ }^{3}$ y fue recién en febrero de 2020 cuando se inauguró una exhibición sobre los orígenes de los primeros pobladores que incluye objetos líticos -bolas de boleadoras y morteros-, fragmentos de cerámica y réplicas de vasijas. En la publicación de la red social Facebook sobre la inauguración de este espacio, se explica que estos elementos buscan dar cuenta "de los diferentes modos de apropiación del territorio y modos de vida que fueron cambiando a través del tiempo" (Museo Histórico Municipal "Alfredo Enrique Múlgura", 2020). Además, en esta sala se alude al momento de la frontera mediante un mural con la imagen del gaucho y del indígena, ambos utilizando bolas de boleadora.

Por último, encontramos en la historia fundacional de los museos de Lezama y San Miguel de Monte algunos elementos comunes que tienen impacto en el modo en que se organizan las exhibiciones de objetos prehispánicos. Ambas instituciones se forjaron en el marco de movimientos locales que encontraron en la gestión del patrimonio, la cultura y la historia, una vía para construir su particularidad dentro de la retórica desarrollista multicultural (Nivón Bolán, 2013). Al igual que se ha registrado en otros lugares del interior del país (Brichetti, 2009; Crespo \& Tozzini, 2014; Ottalagano, 2008), el origen de estos museos se vincula con actores locales interesados en construir narrativas del pasado estableciendo distinciones identitarias en un mundo cada vez más cambiante. En ambos museos, los primeros acervos se formaron a partir de donaciones de diversos elementos que cayeron en desuso durante el siglo $\mathrm{XX}$ - planchas, vestidos, radios, televisores, mobiliario de época, discos, entre otros-, y fueron revalorizados como elementos de distinción local (Prats, 2005). En este contexto, los elementos indígenas recibidos a partir de hallazgos aislados donados por vecinos de la localidad

\footnotetext{
${ }^{3}$ Relevamiento realizado el 4 de mayo de 2018 .
}

(principalmente bolas de boleadora y partes de morteros) fueron conservados y gestionados especialmente como elementos de valor patrimonial, histórico y científico. No obstante, estos objetos se enmarcan en diferentes narrativas en función del perfil de cada institución.

La fundación efectiva del museo de Lezama se encuentra ligada a una comisión pro museo - conformada por un grupo de vecinos en 1992- que recién pudo viabilizar sus proyectos cuando este pueblo adquirió la autonomía administrativa y política en el año 2009. La restitución de la autonomía con la consecuente separación del partido de Chascomús fue reclamada por grupos de vecinos a lo largo de todo el siglo XX (Fernández, 2007). En una entrevista sobre dicho proceso, un profesor de historia de la localidad argumenta que, a diferencia de otros pueblos bonaerenses, en Lezama la presencia de instituciones locales posibilitó un "espíritu de comunidad muy fuerte" ${ }^{4}$. En este marco, el proyecto del museo contribuyó a sostener, legitimar y articular la construcción de un pasado y presente que identificara a esa comunidad diferenciándola de Chascomús. Los objetos indígenas donados fueron integrados a los elementos provenientes de excavaciones sistemáticas y su exhibición se organizó tomando como referencia las salas del museo chascomunense. Debido al reducido espacio, esta institución organiza sus muestras en vitrinas que distinguen "estaciones" temáticas. Los objetos prehispánicos están dispuestos junto con materiales paleontológicos, presentados como patrimonios provenientes de investigaciones arqueológicas llevadas a cabo en el área. La cartelería que acompaña la muestra refiere a una línea temporal que es presentada en la red social Facebook como información que da cuenta de "donde desarrollaron su vida, los antiguos habitantes de nuestra zona" (Museo Histórico de Lezama, 2017).

El Museo Municipal de la Guardia del Monte se gestó con el impulso de un grupo de aficionados y profesores de historia particularmente interesados en recuperar la identidad local de la "época de la frontera" y la historia de Juan Manuel de Rosas en dicha localidad ${ }^{5}$. El contexto de fundación de este museo en plena crisis nacional de diciembre de 2001, fue interpretado por sus gestores como un aporte para "recomponer" la situación social ${ }^{6}$. La reivindicación de la historia rosista tiene su

\footnotetext{
${ }^{4}$ Más información en

https://www.youtube.com/watch?v=7ylvd_0r8X4.

5 Juan Manuel de Rosas fue gobernador de Buenos Aires desde 1829 hasta 1852, con un breve interregno, y estuvo al frente de las relaciones exteriores y de guerra de la llamada Confederación Argentina. En 1820 Rosas adquirió la estancia Los Cerrillos -ubicada en cercanías del fuerte que dio origen al pueblo de San Miguel de Monteentrelazando la historia del pueblo con su controvertida etapa de la historia argentina (Cattaruzza, 2007). Para conmemorar esta etapa de la historia del pueblo se celebra anualmente el Día de la Federación http://monte.gov.ar/turismo/laguardiadelmonte/)

${ }^{6}$ Entrevista con personal de la institución, 16 de julio de 2015. Más información sobre el contexto fundacional puede consultarse en: https://www.youtube.com/watch?v=b4apEN_5LiY\&t=250s.
} 
antecedente en lo que puede considerarse una gran gesta colectiva: el traslado del Rancho de Rosas, llevado a cabo en el año 1987 -a 170 años de su construcción-, desde la ribera del río Salado -donde se encontraba geográficamente- hasta su emplazamiento actual en el casco histórico de la ciudad de San Miguel del Monte. Fue la primera casa de adobe en ser trasladada de toda América del Sur, la labor tomó dos meses de intenso trabajo en el que participaron ingenieros, arquitectos, y técnicos operarios. En articulación con este espacio, el museo amplía y profundiza dicha historia organizando la propuesta expositiva en períodos históricos. Las bolas de boleadoras, puntas de proyectil, una faja pampa y una punta de lanza, se exhiben en la primera sala dedicada a los orígenes poblacionales, identificados con la instalación de la Guardia de Monte a fines de siglo XVIII. Junto a estos objetos, se organiza un panel que incluye, entre otras cosas, un mapa descrito en la cartelería como "referencias cartográficas de la Campaña del Desierto". Destacamos que en este espacio, las bolas de boleadora expuestas son objetos prestados por el Complejo Museográfico Provincial "Enrique Udaondo" (Luján, Buenos Aires), inclusive a pesar de que estos elementos son los que mayor circulación tienen en la microrregión (Salerno, 2018). Como sucede en el resto de los museos, también se incluyen bolas de boleadora en asociación con la figura del gaucho en la exhibición dedicada al "Periodo Federal". Además, en este museo se exponen materiales arqueológicos provenientes de una excavación de rescate que corresponden a evidencias del poblamiento durante los siglos XVIII y XIX (Casadas, Peltzer, \& Prieto, 2005).

En síntesis, desde un punto de vista biográfico, en todos los casos analizados puede decirse que el ingreso de los materiales prehispánicos a los museos constituye una nueva etapa de su vida. En estos nuevos contextos, los fragmentos de cerámica, los restos faunísticos, los materiales de piedra pulida, las puntas de proyectil y los desechos de talla son abordados principalmente como objetos de conocimiento, y puestos en relación con la narrativa de la historia local. En esta, como ya hemos mencionado, lo indígena es una etapa inicial cuya superación representa al crecimiento poblacional. En algunas instituciones, las historias construidas acotan la temporalidad al momento de la frontera. Mientras que en otras, se retoma la información arqueológica de la zona dando cuenta de un proceso de largo plazo. La importancia otorgada a los elementos como objetos de conocimiento los ubica en una temporalidad "científica/ arqueológica" desvinculada de la vida cotidiana que dificulta su abordaje en clave "histórica". Aspecto que contrasta con otro tipo de piezas incluidas en estos museos, principalmente relativas a los siglos XIX y XX, valoradas como elementos distintivos de las experiencias cotidianas y trayectorias de vida de actores locales. Asimismo, la ausencia de información sobre la presencia de indígenas en etapas posteriores a las representadas (identificadas con un tiempo lejano y/o con la etapa de frontera), genera que los objetos y sus historias queden desvinculados del presente de las localidades. Esto se hace particularmente evidente en el caso de las bolas de boleadora utilizadas en las exposiciones sobre la vida rural durante los siglos XIX y XX como un accesorio típico de la figura del gaucho sin que medie una reflexión que problematice el origen y/o su relación con la presencia de indígenas en la campaña bonaerense.

Es importante recordar que los mensajes construidos en estas exposiciones se reelaboran en los tiempos de las visitas (Cousillas, 1997; Dujovne, 1995; entre otros). En esas instancias interactivas, los materiales resultan primordiales no sólo por la información que presentan sino también por los compromisos sensoriales y emocionales que pueden movilizar (Edwards, Gosden, \& Phillips, 2006). Mucho se ha escrito al respecto, y no dudamos de la importancia de esta dimensión para generar conclusiones sobre el impacto efectivo de las narrativas objetivadas en las muestras. No obstante, las exhibiciones constituyen el medio a partir del cual se configura el mensaje museológico dando sustento a posicionamientos específicos respecto de la historia y la identidad local (Pardo, 2000). La centralidad que adquieren los objetos en las muestras da cuenta de su potencial para construir y objetivar determinadas representaciones. En el próximo apartado nos proponemos ampliar la discusión respecto de otras situaciones en las que los objetos se ven involucrados y que pueden impactar en su capacidad de acción.

\section{Las colecciones arqueológicas en las dinámicas institucionales}

En los museos de la microrregión los materiales prehispánicos son acondicionados para su mejor conservación, son clasificados, agrupados y estudiados. Sólo una parte de los conjuntos participa de las propuestas expositivas. Además, algunos objetos son especialmente seleccionados para integrar cajas didácticas, participar de experiencias educativas o lúdicas tanto dentro como fuera de las instituciones ${ }^{7}$. Mientras que otros elementos se encuentran en los depósitos sin una función aparente. En estas diferentes situaciones que viven los objetos dentro de los museos intervienen los trabajadores de la institución y en ocasiones, también participan expertos, estudiosos y/o aficionados de acuerdo con intereses específicos. De esta manera, prestamos especial atención a los diferentes roles que pueden cumplir los objetos dentro de las dinámicas institucionales más allá de las exhibiciones. A partir de los casos analizados observamos en primer lugar que las trayectorias previas y el modo en que los materiales pasan a formar parte de los museos, tiene un impacto diferencial en cómo estos terminan siendo jerarquizados dentro de los mismos. En segundo lugar, los objetos -expuestos

\footnotetext{
${ }^{7}$ Estos recursos son diferentes en cada una de las instituciones y las narrativas que movilizan se encuentran directamente relacionadas con las situaciones interactivas en las que se ponen en juego.
} 
o no- integran las dinámicas institucionales facilitando y/o condicionando relaciones y acciones específicas. En este marco, los objetos contribuyen a gestionar recursos materiales y habilitan vinculaciones con otras instituciones y actores. Por último, los objetos en ocasiones devuelven la mirada sobre la cual reflexionar acerca de aquello que se conserva y/o se expone.

En efecto, las trayectorias previas posibilitan que los objetos tengan mayor o menor posibilidad de generar/ promover vínculos institucionales que impacten en su gestión. Así por ejemplo, se distingue la trayectoria de los materiales prehispánicos del Museo Pampeano de Chascomús cuyo origen refiere a una serie de prácticas y sujetos involucrados en la formación y estudio de una colección privada. Al punto que estas primeras colecciones fueron consideradas para ser exhibidas desde los primeros diseños institucionales como ejemplo de la riqueza científica/histórica del territorio local, y no como parte de la historiografía narrada en el museo (Vigna \& Salerno, 2013). Los múltiples vínculos promovidos a partir de dichas colecciones, tanto en la etapa fundacional del museo como a lo largo de su historia, brindaron a la institución herramientas para gestionar recursos, repensar los espacios expositivos y promover actividades específicas. En contraparte, en el resto de las instituciones analizadas las colecciones de materiales indígenas se formaron principalmente con objetos provenientes de donaciones aisladas que fueron integrando un conjunto mayor a partir de clasificaciones ad hoc. Aunque en estos casos también primó el criterio académico que organiza el abordaje de las piezas en términos de patrimonio arqueológico, estos materiales no movilizaron relaciones de largo plazo entre actores externos y las instituciones museísticas. Estos aspectos incidieron en las exhibiciones: por una parte, los museos de San Miguel de Monte y de Lezama exponen materiales que permiten dar cuenta del entramado relacional que dichos objetos comportan. En el primer caso, se informa que se trata de materiales "prestados" por un prestigioso museo de la provincia de Buenos Aires (Complejo Museográfico Provincial "Enrique Udaondo") y en el segundo caso, se subraya que son objetos recuperados por el equipo de arqueología de la zona, invistiendo de autoridad científica a la muestra. Una situación diferente observamos en los casos de General Belgrano y de Ranchos, donde la inclusión de los materiales prehispánicos en las propuestas expositivas fue considerada luego de diversas remodelaciones.

En cuanto a las relaciones que los materiales promueven dentro de los museos de la microrregión, se destacan los vínculos generados con el equipo de arqueología del que formamos parte. Estas relaciones conllevan un intercambio de saberes, promoviendo acciones específicas y, en ocasiones, contribuyendo a redefinir la importancia de las propias colecciones -en comparación a otros objetos- dentro de las instituciones. En particular, las múltiples miradas que este equipo activó sobre los abundantes fragmentos de alfarería prehispánica que circulan en la zona impulsó vínculos entre grupos de ceramistas locales -interesados en las técnicas de manufactura y diseños prehispánicos-, y los museos. Uno de los efectos más visibles de estos intercambios ha sido la elaboración de réplicas cerámicas que en la actualidad forman parte de las exposiciones en General Belgrano y Chascomús ${ }^{8}$. La presencia de reconstrucciones contribuye a dar cuenta de la complejidad involucrada en la tecnología cerámica, instalando representaciones alternativas sobre la vida cotidiana de las sociedades de cazadores recolectores y pescadores que habitaron el área en tiempos prehispánicos. Además, estas réplicas visibilizan la presencia de una tradición alfarera local, cuyos modos de hacer reorganizan los vínculos con el pasado prehispánico en función de las proyecciones de los alfareros en la actualidad.

Finalmente, otra situación en la que hemos registrado cierta incidencia de los objetos dentro de las dinámicas institucionales, refiere al modo en que los mismos interpelan a los trabajadores del museo. En algunas de las instituciones analizadas hemos registrado la búsqueda de renovar y/o generar nuevos espacios expositivos destinados a la información sobre el origen del poblamiento en la región. Búsqueda que en casi todos los casos constituye un proyecto explicitado durante las entrevistas, motivado por la incomodidad que generan las muestras ya que no reflejan los posicionamientos actuales de quienes integran los museos. Por lo tanto, las mismas continúan generando representaciones que invisibilizan la historicidad y el presente de las poblaciones indígenas. Entendemos que estas miradas críticas se encuentran en sintonía con perspectivas actuales que señalan las limitaciones de las políticas de reconocimiento de la diversidad cultural impulsadas desde fines del siglo $X X$ (Zapata Silva, 2019). El objetivo que buscan las nuevas exposiciones es dar cuenta de la complejidad de la vida de los pobladores prehispánicos a partir de mostrar los diversos materiales utilizados en la vida cotidiana. Así por ejemplo, en el museo de General Belgrano, en el marco de una entrevista, su directora comentó que decidió cerrar un espacio expositivo en el que materiales indígenas eran expuestos junto a fusiles en pos de proyectar su reorganización ${ }^{9}$. Mientras que en el museo de Ranchos, su directora planifica incluir materiales cerámicos en la muestra para dar cuenta de que "los indígenas hacían otras cosas además de boleadoras"10.

Estos proyectos de renovación enfrentan dificultades relacionadas tanto con los escasos recursos disponibles como con las asociaciones que los espacios obligan a

\footnotetext{
8 Particular es el caso del vínculo generado entre el Museo Pampeano de Chascomús y el ISFA, Escuela de Cerámica de Chascomús que estuvo mediado por el desarrollo de trabajos experimentales con el equipo de arqueología durante las últimas dos décadas (ver Francese 2000, rancese et al. 2011, entre otros).

${ }^{9}$ Entrevista realizada el 5 de octubre de 2019.

${ }^{10}$ Entrevista realizada el 5 de octubre de 2019
} 
generar. A partir de estos condicionamientos se organizan las decisiones relativas al modo de exponer los objetos y el armado de guiones. En algunos casos, las limitaciones espaciales llevan a incluir distintos temas en una misma sala y/o vitrina. Particularmente en Chascomús, la asociación entre objetos paleontológicos y arqueológicos se reorganizó estableciendo un recorrido cronológico que separa la temporalidad de las colecciones, enfatizando un tiempo histórico para los últimos. En el caso de General Belgrano, la generación de distinciones temporales entre la temática indígena y gauchesca se resolvió mediante un mural explicativo. Abordar este tipo de problemáticas implica un largo camino en el que se van estableciendo diálogos con arqueólogos, antropólogos y actores locales que colaboran con las instituciones.

En consecuencia, los proyectos de renovación institucional demoran varios años hasta su concreción. Frente a lo cual los entrevistados destacan los usos pedagógicos de los objetos y las relaciones que construyen con las audiencias como estrategias que les permiten poner en tensión las representaciones del pasado indígena presentes en las muestras. Por ejemplo, en el museo de Ranchos, desde la oralidad se busca retomar el pasado indígena previo a la etapa de frontera discutiendo la temporalidad plasmada en la sala Los orígenes de Ranchos. Si bien en este trabajo no profundizamos en el modo en que se desarrollan este tipo de estrategias, nos llaman la atención sobre la incomodidad que los trabajadores de los museos tienen respecto de los espacios expositivos y del complejo entramado institucional que conlleva realizar un cambio en las exposiciones. Cabe destacar que, lejos de tratarse de un caso aislado, en diferentes museos del interior del país se ha observado el desarrollo de actividades dirigidas a discutir las narrativas folklorizantes plasmadas en las exhibiciones (Brichetti, 2009; Caro Petersen, Colombo, Weitzel, Mazzia, \& Flegenheimer, 2016; Chaparro, 2017; Endere, 2004; Ottalagano, 2008; entre otros)

\section{Reflexiones finales}

En este trabajo propusimos un análisis centrado en los objetos arqueológicos y su biografía para ampliar la mirada respecto de las narrativas presentes en las exhibiciones de los museos de la microrregión del río Salado. Cuando visitamos estas instituciones nos encontramos con los materiales arqueológicos alojados en las vitrinas, dispuestos aisladamente, o en asociación con elementos que remiten a diferentes temporalidades -paleontológicos y/o de temática gauchesca-. Estas exhibiciones nos llevan a reflexionar sobre la tendencia hacia la homogeneización de distintas etapas del pasado y, en este marco, pensar a los objetos como elementos estáticos. Sin embargo, los sentidos en torno a la temporalidad que estos conllevan cambian no solo de acuerdo con las asociaciones espaciales de la exhibición, sino también en función de las múltiples relaciones que éstos movilizan. A partir de los casos analizados, observamos que la historia de los materiales dentro de las instituciones nos puede permitir trazar una línea dinámica de su rol dentro de ellas. Desde este lugar, podemos complejizar los motivos que hacen que a pesar de referir a una historia indígena de larga duración, estos elementos continúen reproduciendo una historia olvidada y/o silenciada que en la actualidad es pensada críticamente, tanto desde la museología como desde las disciplinas históricas y antropológicas.

En los museos analizados observamos que los materiales prehispánicos, pese a estar descontextualizados, guardados en depósitos o expuestos, interpelan a pensar el pasado de manera dinámica y en la multiplicidad de significados que hay detrás de un objeto. De esta manera, aparecen asociados de forma reiterativa en tres temporalidades en las que diferentes sujetos históricos son protagonistas: historia prehispánica, época de frontera y la vida rural del siglo XIX. Esta configuración permite identificar la existencia de distintas perspectivas sobre el pasado indígena dentro de la microrregión. No obstante, encontramos como punto en común que los materiales indígenas son presentados como elementos "extranjeros" que contribuyen a formar representaciones de alteridad. Esto se debe en parte a que en estas localidades la historia indígena es difícil de asumir como parte de la propia historia. Otros factores que contribuyen con esta dificultad se relacionan, por un lado, con la exacerbación de las memorias asociadas a los migrantes europeos promovidas por la historiografía tradicional. Por otro lado, con las narrativas arqueológicas que ubican a los objetos indígenas en una temporalidad científica desvinculada de la vida cotidiana.

Finalmente, en este trabajo buscamos un acercamiento a la cultura material que aborde las múltiples historias que nos cuentan los objetos y el modo en que estos son parte de distintas temporalidades. Este enfoque nos permitió identificar diferentes dimensiones que hacen a la vida de los materiales indígenas dentro de las instituciones museológicas y que no pueden reducirse a su participación en espacios expositivos. En la actualidad, en algunos museos analizados observamos que el vínculo con la materialidad promueve un cambio en el modo de abordar los objetos que se expresa en la búsqueda de renovación de exposiciones. Subrayamos la complejidad de este tipo de procesos y advertimos sobre la importancia de ir más allá de las representaciones organizadas en las muestras. Dejamos abierto el debate para discutir cómo podemos contribuir, en tanto profesionales de la arqueología, para que estos museos locales superen las narrativas históricas lineales que promueve la modernidad, enriqueciendo la historia con nuevas voces e interpretaciones.

Buenos Aires, 22 de mayo de 2020

\section{Agradecimientos}

Este trabajo fue realizado en el marco del proyecto 
FILOCYT FC19-070 (2019-2021) de la Facultad de Filosofía y Letras, UBA. Res. (CD) 1570. Expresamos nuestra gratitud al personal de los cinco museos de la microrregión, así como a los evaluadores y a Clara Rodríguez, Alejandra Pupio, Verónica Stáffora, María Julia Cardinal y Magdalena Frère, cuyas lecturas atentas nos ayudaron a enriquecer el manuscrito.

\section{Bibliografía}

Baganoli, V. (2019). El patrimonio arqueológico posthispánico del sur bonaerense a través de las colecciones. Arqueología, 25(1), 95-117.

Balbé, W. (2019). Máscaras chané: alteridad y temporalidad en las visitas escolares del Museo Nacional del Hombre. Recuperado de Corpus Archivos virtuales de la alteridad americana website: http://journals.openedition.org/ corpusarchivos/3140

Blache, M. (1991-1992). Folklore y nacionalismo en la Argentina: su vinculación de origen y su desvinculación actual. Runa, 20, 69-89.

Blasco, M. É. (2007). Los museos históricos en la Argentina entre 1889 y 1943. Programa Buenos Aires de Historia Política Del Siglo XX, 2, 109-129. Recuperado de http:// rodolfogiunta.com.ar/Patrimonio/Biblio 036.pdf

Blasco, M. É. (2011). Un museo para la colonia. El Museo Histórico y Colonial de Luján (1918-1930). Rosario: Prohistoria.

Bona, C. P. (1989). Museo histórico regional. Celebra hoy sus bodas de Plata. Tiempo de Ranchos, p. 2.

Brichetti, I. E. (2009). Museos regionales en el Sudeste de la Provincia Buenos Aires. Una aproximación a la problemática patrimonio arqueológico. Intersecciones En Antropología, 10, 17-25.

Briones, C. (2005). Cartografías Argentinas. Políticas indigenistas y formaciones provinciales de alteridad (C. Briones, Ed.). Buenos Aires: Antropofagia.

Caro Petersen, Á., Colombo, M., Weitzel, C., Mazzia, N., \& Flegenheimer, N. (2016). Museo de Ciencias Naturales de Necochea, 73 años. En J. Athor \& C. Celsi (Eds.), La Costa Atlántica de Buenos Aires. Naturaleza y patrimonio cultural. (pp. 617-622). Buenos Aires: Fundación de Historia Natural Félix de Azara.

Casadas, M. I., Peltzer, M. E., \& Prieto, N. (2005). Análisis interinstitucional sobre materiales constructivos provenientes del Sitio Arqueológico Escuela No 16 de San Miguel del Monte, Provincia de Buenos Aires. Recuperado de https://repositoriosdigitales.mincyt.gob.ar/vufind/ Record/CICBA_be8cedf7233c63bee18f94404ddce2b4
Cattaruzza, A. (2007). Los usos del pasado. La historia y la política argentinas en discusión, 1910-1945. Buenos Aires: Sudamericana.

Chaparro, G. (2017). Los avatares de una colección en ámbitos municipales: el Museo Etnográfico Dámaso Arce (Olavarría, Argentina). Boletim Do Museu Paraense Emílio Goeldi. Ciências Humanas, 12(2), 595-613.

Clifford, J. (1995). Dilemas de la cultura. Antropología, literatura y arte en la perspectiva posmoderna. (Gedisa, Ed.). España.

Conforti, M. E., \& Endere, M. L. (2012). La imagen de la arqueología y el patrimonio arqueológico en los medios de comunicación. Un análisis sobre la prensa gráfica local. Antípoda. Revista de Antropología y Arqueología, 14(enero-junio), 163-184.

Cousillas, A. M. (1997). Los estudios de visitantes a museos: fundamentos generales y principales tendencias. Recuperado de https://www.equiponaya. com.ar/articulos/museologia02.htm

Crespo, C., \& Tozzini, M. A. (2014). Memorias silenciadas y patrimonios ausentes en el Museo Histórico de El Hoyo, Comarca Andina del Paralelo $42^{\circ}$, Patagonia Argentina. Antípoda. Revista de Antropología y Arqueología, 19(mayo-agosto), 21-44.

Dujovne, M. (1995). Entre musas y musarañas. Una visita al museo. Buenos Aires: Fondo de Cultura Económica.

Edwards, E., Gosden, C., \& Phillips, R. (2006). Sensible Objects. Colonialism, Museums and Material Culture (E. Edwards, Ed.). United Kindom: Berg.

Endere, M. L. (2004). Arqueología, patrimonio y comunidad local. El caso de Arroyo Seco 2, Partido de Tres Arroyos, Provincia de Buenos Aires. En G. Martínez, M. Guitiérrez, R. Curtoni, M. Berón, \& P. Madrid (Eds.), Aproximaciones arqueológicas pampeanas: teoría, métodos y casos de aplicación contemporáneos (pp. 451-468). Olavarría: INCUAPA-UNICEN.

Fernández, M. I. (2007). La creación de municipios en la provincia de Buenos Aires: nuevos discursos y viejas prácticas. Revista Espacios de Critica y Producción, 35(2), 10-19. Recuperado de http://repositorio.filo.uba. ar/handle/filodigital/7660.

Flegenheimer, N. (2001). Las ocupaciones de la transición Pleistoceno-Holoceno: una visión sobre las investigaciones en los últimos 20 años en la Región Pampeana. X Congreso Nacional de Arqueología Uruguaya. Montevideo: MS.

Francese, A. (2000). Secuencia de experimentación cerámica en el sitio arqueológico "La Guillerma". Actas 
de $6^{\circ}$ Jornadas de Arqueología en la Provincia de Buenos Aires: uso del territorio y vida cotidiana, 26-30.

Francese A., Migueliz, G., González, M. I. y Frère, M.M. (2011). Proyecto de intercambio científico, artístico y pedagógico: ISFA Escuela de Cerámica de Chascomús e Instituto de Arqueología de la Facultad de Filosofía y Letras UBA. $1^{\circ}$ Congreso Docente de Experiencias Educativas Transformadoras, DGE, Provincia de Buenos Aires.

García, S. (2011). Museos provinciales y redes de intercambio en la Argentina. En A. Heizer \& M. Lopes (Eds.), Coleccionismos, prácticas de campo $e$ representações (pp. 75-91). Campina Grande: EDUEPB.

Gosden, C. (2005). What do objects want? Journal of Archaeological Methods and Theory, 12(3), 193-211. https://doi.org/10.1007/s10816-005-6928-x

Gosden, C., \& Marshall, Y. (1999). The cultural biography of objects. World Archaeology, 31(2), 169-178.

Hamilakis, Y. (2015). Arqueología y los sentidos. Experiencia, Memoria, y Afecto. Madrid: JAS Arqueología.

Hutson, S. R. (2002). Built space and bad subjects: Domination and resistance at Monte Alban, Oaxaca, Mexico. Journal of Social Archaeology, 2(1), 53-80.

Huyssen, A. (2002). En busca del futuro perdido. Cultura y memoria en tiempos de globalización. México: Fondo de Cultura Económica.

Ingold, T. (2007). Materials against materiality. Archaeological Dialogues, 14(1), 1-16. https://doi. org/10.1017/S1380203807002127

Lucas, G. (2012). Understanding the Archaeological Record. https://doi.org/10.1017/CBO9780511845772

Mandrini, R. J. (2007). La historiografía argentina, los pueblos originarios y la incomodidad de los historiadores. Revista Quinto Sol, Facultad de Ciencias Humanas. Universidad de La Pampa, 11, 19-38.

Menares, C., Mora, G., \& Stüdemann, N. (2007). Primera Exploración Etnográfica para la Nueva Museografía Museo Mapuche de Cañete. Santiago de Chile: Trashumante, Estudios Culturales.

Miller, D. (2005). Materiality (D. Miller, Ed.). Durham: Duke University Press.

Museo Histórico de Lezama. (2017). Publicación de Facebook. 20 de julio. https://www.facebook.com/photo. php?fbid=807116696113319\&set=pcb.8071301894453 03\&type=3\&theater
Museo Histórico Municipal "Alfredo Enrique Múlgura". (2020). Publicación de Facebook. 21 de febrero. https://www.facebook.com/1997Museo/photos/pcb.310 1089399935855/3101088976602564/?type=3\&theater

Nagy, M. A. (2013). Los museos de la última frontera bonaerense y sus narrativas acerca de los pueblos indígenas. Revista Del Museo De Antropología, 6(1), 79-90. https://doi.org/ 10.31048/1852.4826.v6.n1.5506

Nagy, M. A. (2017). Memorias, historias de vida y trayectorias indígenas en la provincia de Buenos Aires. Memoria Americana. Cuadernos De Etnohistoria, 25(2), 168-186. https://doi.org/10.34096/mace.v25i2.4035

Nivón Bolán, E. (2013). Las políticas culturales en América Latina en el contexto de la diversidad. En Hegemonía cultural y políticas de la diferencia (pp. 23-46). Recuperado de http://biblioteca.clacso.edu.ar/clacso/ gt/20130718114959/eduardo_bolan.pdf

Olsen, B. (2003). Material culture after text: re-membering things. Norwegian Archaeological Review, 36(2), 87-104. https://doi.org/10.1080/00293650310000650

Ottalagano, F. (2008). Acerca de pequeños museos en pequeñas comunidades: el caso de Villa Cañás. Apuntes Del CEAR, 2, 31-37.

Pardo, J. (2000). Ideas e ideología en el proyecto museológico. Revista Museo, 5, 61-71.

Podgorny, I. (1999). De la antigüedad del hombre en el Plata a la distribución de las antigüedades en el mapa: los criterios de organización de las colecciones antropológicas del Museo de la Plata entre 1897 y 1930. Ist. Cienc. Saude-Manguinhos, 6(1), 81-101. http:// dx.doi.org/10.1590/S0104-59701999000200004

Poggi, M., \& de Arce, A. (2018). Se hace camino al andar... museos rurales y redes culturales en la cuenca del salado (buenos aires, argentina). En Asociación Orden de la Caminería (Ed.), VI Congreso Virtual sobre historia de las vñias de comunicación (pp. 315-332). Recuperado de https://dialnet.unirioja.es/servlet/ articulo?codigo $=6846959$

Politis, G., \& Madrid, P. (2001). Arqueología Pampeana: Estado actual y Perspectivas. En Historia Argentina Prehispánica. Tomo /l (p. 952). Córdoba: Brujas.

Prats, L. (2005). Concepto y gestión del patrimonio local. Cuadernos de Antropología Social, Instituto de Cs. Antropológicas, Facultad de Filosofía y Letras, UBA, 21, 17-35.

Prieto, A. (1988). EL discurso criollista en la formación de la Argentina moderna. Buenos Aires: Sudamericana. 
Pupio, A. (2005). Coleccionistas de objetos históricos, arqueológicos y de ciencias naturales en museos municipales de la Provincia de Buenos Aires en la década de 1950. História, Ciências, Saúde-Manguinhos, 12, 205-229.

Quesada, M., Moreno, E., \& Gastaldi, M. (2007). Narrativas arqueológicas públicas e identidades indígenas en Catamarca. Revista Arqueologia Pública, 2(1 [2]), 57-71. https://doi.org/10.20396/rap.v2i1.8635811

Rodríguez, M. E. (2013). Cuando los muertos se vuelven objetos y las memorias bienes intangibles: tensiones entre leyes patrimoniales y derechos de los pueblos indígenas. En C. Crespo (Ed.), Tramas de la diversidad. Patrimonio y Pueblos Originarios (1st ed., pp. 67-100). Buenos Aires: Antropofagia.

Rufer, M. (2009). Escenas. Memoria pública y usos del pasado en contextos poscoloniales. México: El Colegio de México A.C.

Salerno, V. M. (2014). Trabajo arqueológico y representaciones del pasado en la provincia de buenos aires (Martín Góm). Ciudad Autónoma de Buenos Aires: Editorial de la Facultad de Filosofía y Letras, UBA.

Salerno, V. M. (2016). Apropiación de objetos arqueológicos en la microrregión del río Salado bonaerense. Revista de Antropología Del Museo de Entre Ríos, 2(2), 93-97.

Salerno, V. M. (2018). Testimonios que nos da la tierra. Apropiación de objetos arqueológicos en la provincia de Buenos Aires, Argentina. Antipoda. Revista de Antropología y Arqueología, 31, 89-107. http://dx.doi. org/10.7440/antipoda31.2018.05

Salerno, V. M., \& Vigna, M. S. (2011). Acercamiento a la construcción del pasado prehispánico en una sala del Museo Pampeano de Chascomús entre 1939 y 1992. Revista Arqueología. Instituto de Arqueología. FFyL.
UBA, 18, 181-207.

Sánchez Azcárate, F. (2016). Contrastes en torno a la construcción del pasado indígena regional en espacios museográficos del sudeste bonaerense: un acercamiento desde las historias institucionales. Páginas Revista Digital de La Escuela de Historia de La Universidad Nacional de Rosario, 8(18 (septiembre-diciembre)), 78-96. Recuperado de https://revistapaginas.unr.edu.ar/index. php/RevPaginas/article/view/237/293

Smith, L. (2011). El espejo patrimonial ¿ilusión narcisista o reflexiones múltiples? Antípoda. Revista de Antropología y Arqueología, 12, 39-63.

Sterling, G. (2009). Configuración y omisiones en la construcción de las representaciones museográficas en la triple frontera. En IX Encuentro Nacional y III Congreso Internacional de Historia Oral de la República Argentina Los usos de la Memoria y la Historia Oral. Buenos Aires: Dirección General de Patrimonio e Instituto Histórico.

Thomas, N. (1991). Entrangled objects. Exchange, material culture and colonialism En the pacific. Cambridge: Harvard University press.

Tilley, C. (1994). A phenomenology of landscape. Place, paths and monuments. Oxford: Berg.

Vigna, M. S., \& Salerno, V. M. (2013). Objetos cotidianos objetos científicos: representaciones del pasado en el museo pampeano de Chascomús. XIV Jornadas Interescuelas. Departamento de Historia de La Facultad de Filosofía y Letras. Universidad Nacional de Cuyo. Recuperado de https://www.aacademica.org/000010/857\%0A

Zapata Silva, C. (2019). Crisis del multiculturalismo en América Latina. Conflictividad social y respuestas críticas desde el pensamiento político indígena (1st ed.). Costa Rica: Editorial Universidad de Costa Rica. 